\title{
DIREITO EMPRESARIAL: UMA VISÃO GLOBAL DA SOCIEDADE EMPRESÁRIA.
}

\author{
Pedro Teófilo de Sá, Joice Monteiro Lira Tiyoda, Lilian Aparecida Guiotoku
}

Universidade do Oeste Paulista - UNOESTE, Curso de Ciências Contábeis, Presidente Prudente, SP. E-mail: teofilopp@gmail.com

\section{RESUMO}

O objetivo deste trabalho é demonstrar que o direito empresarial disciplina a criação, registro e a obrigatoriedade da escrituração dos livros contábeis, partindo de uma pesquisa bibliográfica qualitativa. Como resultados, apurou-se que o empresário deve, antes do início da atividade empresarial, proceder ao registro na junta comercial e respeitar o dever de escrituração. Ao final pôde-se concluir que o direito empresarial é de grande importância para a estruturação e criação e manutenção da sociedade empresária, já que esta deve seguir as formalidades intrínsecas e extrínsecas do empresário, com a obrigação de manter o livro diário, que é de grande importância para a sociedade, pois, no futuro, servirá de suporte para eventual pedido de recuperação de empresas e em eventual processo de falência.

Palavras-chave: Direito Empresarial. Obrigações. Sociedades Empresárias. Micro e Pequenas Empresas. Recuperação de empresas.

\section{BUSINESS LAW: AN OVERVIEW OF THE ENTREPRENEUR COMPANY.}

\begin{abstract}
The objective of this work is to demonstrate that the business law governs the creation, registration and mandatory bookkeeping of accounting books, according a qualitative bibliographic search. As a result, it was found that the entrepreneur must, prior to the start of business activity, proceed with the registration in the commercial registry and comply with the obligation of bookkeeping. At the end it could be concluded that the right business is of great importance for the structuring and creation and maintenance of the business company, as this should follow the intrinsic and extrinsic formalities of businessman, with the obligation to keep the diary book, which is major importance for a company, because in the future will support any request for recovery companies and possible bankruptcy process.

Keywords: Business Law. Obligations. Business Societies. Micro and Small Organizations. Recovery companies.
\end{abstract}




\section{INTRODUÇÃO E OBJETIVO}

Nos dias atuais é cada vez maior o número de pessoas que pretendem inciar a atividade comercial. Para isso, a legislação civil trouxe a necessidade do seu registro no órgão competente, antes mesmo do incício da atividade. Vê-se então que essa relação entre a sociedade e os sócios recebe a disciplina de um ramo do direito que vai se ater ao processo de criação, administração e extinção das sociedades.

O Estado, ao desenvolver a sua função regulatória, certamente tem uma finalidade, a de controlar o exercício da atividade comercial, seguido da consequência lógica, a arrecadação tributária, como forma de aquisição de receitas para a subsistência e manutenção da máquina pública.

Para disciplinar essa situação da empresa e sua atividade, o Estado lança mão de instrumentos legislativos, a ele reservados e garantidos pela Constituição Fedral de 1988. Assim, a licitude e coerência desse controle passa pelo Direito, esse conjunto de regras normatizador da realidade social.

Fala-se então do Direito Empresarial, um ramo do direito privado que estuda e regulamenta as relações empresariais, que envolvem empresa e empresário. A empresa, é um ente autônomo usado como objeto para as relações jurídicas, e o empresário é um sujeito que assume direitos e deveres.

Separadas as duas figuras, o empresário é aquele que exerce com profissionalismo uma atividade econômica organizada na produção ou circulação de bens ou serviços, isto é, explora a empresa, que tem na sua atividade a finalidade lucrativa.

Estas definições e outras disposições acerca do Direito Empresarial estão previstas no Código Civil vigente em seu Livro II, "Direito de Empresa", compreendido entre os artigos 966 e 1.195.

Assim, para que o empresário tenha a sua atividade regularizada deverá cumprir o art. 967 do Código Civil que impõe a obrigatoriedade da inscrição do empresário na Junta Comercial antes do início de suas atividades.

Após seguir essa rotina legal o empresário deverá observar que a lei lhe impõe obrigações, dentre elas as de manter a escrituração de forma regular.

Então, observa-se que o futuro empresário deverá seguir dois caminhos, o da inscrição da empresa e o do cumprimento da escrituração que terá reflexos em possível pedido de falência e recuperação. 
O não cumprimento da obrigação de se inscrever na Junta Comercial, não garante o direito para o pedido de falência e de recuperação judicial, além de causar a ineficácia probatória dos livros contábeis e a responsabilidade ilimitada dos seus sócios (COELHO, 2013, p. 69).

Em virtude disto, o presente estudo tem como objetivo demonstrar que o direito empresarial disciplina a criação, registro e a obrigatoriedade da manutenção da escrituração dos livros contábeis empresariais.

\section{METODOLOGIA}

O presente artigo apresenta uma abordagem qualitativa, e tem como instrumento de coleta de dados para a sua realização, a pesquisa bibliográfica, através de livros, revistas, artigos científicos, especializadas e sites jurídicos.

\section{RESULTADOS}

O Direito Empresarial é o responsável pela regulamentação das sociedades empresárias estabelecidas em nosso país, que surgem com o intuito de praticar os atos de empresa. Este ente, a empresa, para estar de acordo com a lei, antes de começar a operar deve fazer o seu registro na Junta Comercial, depois, continuando as atividades elas devem escriturar o(s) livro(s) e as demonstrações que lhe cabem obrigatoriamente.

As sociedades podem ser classificadas em simples ou empresárias, e conforme o objetivo do presente artigo, serão estudadas as empresárias, que devido ao caráter comercial podem ser classificadas em micro ou pequena empresa, critério este, estabelecido de acordo com a sua receita bruta anual. E ainda caso se encontrem em dificuldades, podem requerer a recuperação seja ela extra judicial ou judicial.

\section{DISCUSSÃO}

O Registro de Empresa tem o propósito de legalizar o exercício da atividade comercial e de conceder a personalidade jurídica, quando passará a ter vida distinta da dos seus sócios. Então, somente a partir do registro que se tem o nascimento da pessoa jurídica, também conhecida como uma ficção da lei, por ser um ser inanimado, com vida e patrimônio próprio, titular de direitos e obrigações.

Decorrente do registro, o empresário é obrigado a seguir um sistema de contabilidade, mecanizado ou não, a exemplo da escrituração em livros contábeis e levantar anualmente dois 
demonstrativos financeiros, o balanço patrimonial e a demonstração do resultado econômico (JÚNIOR, 2012, p. 49).

Manter a escrituração em ordem demonstra a real situação patrimonial e econômica de uma empresa, o que propicia verificar se as exigências fiscais estão sendo atendidas e, em algumas hipóteses até podem ser utilizados para fazer prova em juízo, tanto contra quanto a favor do empresário.

Para que os livros tenham efeito jurídico é necessário que a escrituração atenda aos requisitos intrínsecos e extrínsecos previstos pela lei.

Segundo Ramos (2012, p. 81), a escrituração deverá seguir duas formalidades, a primeira é chamada de intrínsecas ou internas, por isso a escrituração deve ser realizada em idioma e moeda nacionais, seguindo uma linguagem técnica contábil, além de uma ordem cronológica de dia, mês e ano, sem intervalos em branco, entrelinhas, borrões, rasuras, emendas ou transporte para as margens. Já pela segunda formalidade a extrínseca, ou externa, refere-se a autenticação do livro na Junta Comercial antes do início da escrituração.

Nessa mesma linha de raciocínio dever-se abordar acerca de duas espécies de livros empresariais, comum e os especiais, sem menosprezo aos demais, como o livro caixa, registro de duplicatas e outros.

O livro obrigatório comum é aquele que todos os empresários deverão possí-lo, para manter os seus registros em dia. Atualmente o único livro comum obrigatório a todo empresário é o Livro Diário, onde são registradas todas as operações diárias do exercício da empresa. Pela análise desse livro é possível saber sobre a vida da empresa, como ela se desenvolve. Dentre tantos aspectos e funções que envolvem esse livro, desta-se a necessidade do empresário entrega-lo ao administrador judicial, em eventual processo de falência. Consequentemtente, se não for entregue acarreta crime falimentar. Por isso esse livro é muito importante nas sociedades Limitadas, uma espécie amplamente utilizado no meio empresarial nacional.

Por outro lado, o livro obrigatório especial é aquele imposto a determinadas empresas, como por exemplo, o Livro de Registro de Ações Nominativas que é exclusivo e obrigatório as Sociedades Anônimas, e servem para registro exclusivo das ações denominadas de nominativas e de suas circulações.

Somente deverão atender a esse requisito da escrituração aquelas sociedades que forem tidas como empresárias. 
Conforme o ordenamento jurídico brasileiro, as sociedades se dividem em simples e empresárias, pois nem todas podem ser classificadas sociedades empresárias, já que para que a atividade seja considerada empresarial deve haver a organização dos fatores de produção.

Mamede (2015, p. 40) afirma que, as empresárias exercem a atividade econômica organizada e são aquelas que desempenham atividades com intuito lucrativo, já nas simples, não existe caracterísitica comecial, por isso, não se identifica tal organização na produção ou circulação de bens e serviços, exploram o capital intelectual, ou uma atividade artística, literária ou de natureza científica.

Outra característica que as diferenciam são os órgãos em que se faz o registro, as empresárias devem ser registradas nas Juntas Comerciais do seu estado, e as simples no Cartório de Registro de Pessoas Jurídicas.

É importante registrar o recorte epistemológico, pois o objeto de estudo aqui desenvolvido se relaciona ao projeto sobre a recuperação de empresas, por isso, estudar-se-á, neste artigo, as sociedades empresárias, pois são elas que podem usufruir ou requerer uma possível recuperação judicial ou extrajudicial.

É certo que ao se criar uma sociedade empresária os sócios precisam comungar de um único interesse, o de praticar atos de comércio com finalidade lucrativa, por isso podem optar pela forma que melhor atenda aos seus interesses.

De acordo com Ramos (2015, p. 212), as sociedades empresárias podem se organizar nos seguintes tipos: sociedade em nome coletivo $(\mathrm{N} / \mathrm{C})$, sociedade em comandita simples $(\mathrm{C} / \mathrm{S})$, sociedade em comandita por ações (C/A), sociedade limitada (Ltda.) e a sociedade anônima (S/A).

A Sociedade em Nome Coletivo possui o capital social fracionado em quotas, sendo composta unicamente por pessoas físicas, no que os sócios respondem ilimitada e solidariamente pelas obrigações sociais.

Na Sociedade em Comandita Simples o capital social também é dividido em quotas, porém, possui dois tipos de sócios, os Comanditados, pessoas físicas que possuem responsabilidade ilimitada e solidária com as obrigações da sociedade. Observe que somente os sócios comanditados podem ser administradores da empresa, enquanto que os Comanditários podem ser pessoas físicas ou jurídicas, e suas responsabilidades serão limitada ao valor de suas quotas. Ademais, estes não podem praticar atos de gestão, mas, podem participar das deliberações da empresa, fiscalizar a administração e receber poder de procurador para determinados negócios (MAMEDE, 2015, p. 97). 
Outra espécie é a Sociedade em Comandita por Ações, a este tipo societário aplicam-se as normas da sociedade anônima, trazidas pela lei 6.404/76. Ela tem o capital social fragmentado em ações e possui dois tipos de sócios, um com responsabilidade limitada ao valor de suas ações, que são os sócios investidores, e outro com responsabilidade ilimitada, àqueles que exercem função de administrar a sociedade.

A Sociedade Limitada é o tipo societário mais utilizado no Brasil, pela simples razão de que os sócios possuem responsabilidade limitada ao valor de suas quotas. Estando o capital social totalmente integralizado a sociedade responde por suas dívidas até o limite de seu capital social. Exaurido o patrimônio da sociedade e, restando débitos a serem pagos, os credores deveram suportar o prejuízo, pois o patrimônio particular dos sócios não poderá ser alcançado, devido a separação patrimonial.

Por fim, a última espécie societária comumente empregada na prática comercial brasileira é a Sociedade Anônima, também conhecida como Companhia, que tem seu capital social dividido em ações, ou seja, papeis, também conhecidos como valores mobiliários, lançados no mercado de capitais pela sociedade com a finalidade de captar recursos. Nesta sociedade, os sócios possuem responsabilidade limitada ao valor de emissão das ações que subscrever. A Sociedade Anônima pode ser formada de duas formas, 1)sociedade de capital fechado ou, 2)sociedade de capital aberto, porém, somente esta última poderá expor suas ações à venda no mercado de ações.

Depois de conhecer, rapidamente, as possíveis espécies de sociedades mercantis ou comeciais, é preciso lembrar que essas empresas terão enquadramento de acordo com o faturamento bruto anual.

Aqui interessa o estudo das sociedades que poderão ser classificadas como micro ou pequenas empresas, devendo ficar claro que estas recebem um tratamento diferenciado concedido pela Lei Complementar 123/2006, que tem como objetivo estimular e desenvolver os pequenos negócios afim de gerar novos empregos e contribuir com a riqueza do país.

Em conformidade com a esta Lei Geral, Ramos (2012, p. 768) diz que são consideradas microempresas e empresas de pequeno porte, as sociedades empresárias, empresa individual de responsabilidade limitada (EIRELI) e o empresário individual, devidamente registrados no órgão de registro de empresas de acordo com o caso.

A classificação, segundo Ramos (2012, p. 769) em micro ou pequena empresa é feita com base na receita bruta anual, vejamos:

a) no caso de microempresa, auferir receita bruta anual igual ou inferior a $\mathrm{R} \$ 360.000,00$ (trezentos e sessenta mil reais); 
b) a empresas de pequeno porte, deve ter receita bruta anual superior a $R \$ 360.000,00$ (trezentos e sessenta mil reais) e igual ou inferior a $\mathrm{R} \$ 3.600 .000,00$ (três milhões e seiscentos mil reais);

c) já o microempreendedor individual, deve ter receita bruta anual de até $R \$ 60.000,00$ (sessenta mil reais).

É importante esclarecer que os valores que servem de base para o enquadramento sofrem variações, e para que haja precisão quanto a tais valores é indispensável que seja consultado o site da receita federal.

Independente do tipo da sociedade ou do enquadramento por ela adotado há exigência do cumprimento da forma de escrituração, isto porque caso ela pretenda iniciar um processo de recuperação, é fundamental além da inscrição como pessoa jurídica, a manutenção da escrituração contábil.

\section{CONCLUSÃO}

O presente trabalho se propôs a demonstrar que o direito empresarial disciplina a criação, registro e a obrigatoriedade da manutenção da escrituração dos livros contábeis empresariais.

Com o desenvolvimento do conteúdo, abordou-se o direito comercial e a sua relação com o registro da empresa, além dos livros obrigatórios que o empresário deverá manter. Com isso, pode-se constatar que somente se beneficiarão do direito empresarial as sociedades empresárias que estiverem inscritas na Junta Comercial do seu respectivo estado. Além do mais, elas devem seguir formalidades intrínsecas e extrínsecas, com a obrigação de manter o livro diário, que é um livro obrigatório de grande importância para a vida da sociedade empresária, já que servirá de suporte para eventual pedido de recuperação de empresas e em eventual processo de falência deverá ser imediatamente entregue ao administrador judicial, sob pena de não o fazer e cometer crime falimentar.

Seguindo essa mesma linha pode-se observar que o direito empresarial cuida de vários tipos de sociedades empresárias, dentre elas as sociedade em nome coletivo, sociedade em comandita simples, sociedade em comandita por ações, sociedade limitada e a sociedade anônima.

Cada uma dessas sociedades tem sua característica própria e não se confundem. No entanto têm algo em comum, para serem definidas como empresárias, necessitam do registro na Junta Comercial e serão consideradas micro ou pequena empresa dependendo do valor do faturamento anual. 
Por todos esses aspectos, vê-se que a observância do direito empresarial é de suma importância para a estruturação, criação e manutenção da sociedade, pois interfere no seu dia a dia. No tocante à manutenção se inserem as obrigações dos comerciantes de manter a escrituração dos livros, pois estes servirão de suporte em eventual processo de falência ou recuperação de empresas.

\section{REFERÊNCIAS}

COELHO, F. U. Manual de Direito Comercial: direito de empresa. 25.ed. São Paulo: Saraiva, 2013.

DORIA, D. Curso de Direito Comercial. 13.ed. rev. Atual. São Paulo: Saraiva, 2008.

GOMES, F. B. Manual de Direito Comercial: de acordo com a nova lei de falência e recuperação de empresas. 2.ed. São Paulo: Manole, 2007.

GONÇALVES, M. G. V. P. R.; GONÇALVES, V. E. R. Direito Comercial: direito de empresa e sociedades empresárias. 3.ed. São Paulo: Saraiva, 2010.

GONÇALVES NETO, A. A. Direito de Empresa: comentários aos artigos 966 a 1.195 do Código Civil; 2a edição. rev. atual. e ampl.; São Paulo: Editora Revista dos Tribunais, 2008.

JÚNIOR, W. F. Manual de Direito Comercial. 13.ed. São Paulo: Atlas, 2012.

MAMEDE, G. Manual de Direito Empresarial. 9.ed. São Paulo: Atlas, 2015.

NEGRÃO, R. Manual de Direito Comercial e de empresa, vol.1; 6a edição ver. e atual.; São Paulo: Saraiva, 2008.

Observatório da Lei Geral da Micro e Pequena Empresa. Disponível em: <http://www.leigeral.com.br/portal/main.jsp?lumPageld=FF8081812658D379012665B59AC01CE8 >Acesso em: 27 abr. 2015.

RAMOS, A. L. S. C. Direito Empresarial Esquematizado. 2.ed. São Paulo: Método, 2012.

RAMALHO, Z. L. A. Empresa na ordem econômica: princípios e função social. Curitiba: Juruá, 2009.

REQUIÃO, R. Curso de Direito Comercial, vol. 1; 32ạ edição; São Paulo: Saraiva, 2013.

TEIXEIRA, T. Direito Empresarial Sistematizado: doutrina e prática. 2a edição; São Paulo: Saraiva, 2013. 